Published as: Joshua M. Pearce, "Appropedia as a Tool for Service Learning in Sustainable Development", Journal of Education for Sustainable Development, 3(1), pp.47-55, 2009. http://jsd.sagepub.com/cgi/content/abstract/3/1/45

\title{
Appropedia as a Tool for Service Learning in Sustainable Development
} Joshua M. Pearce

Joshua M. Pearce is an assistant professor of renewable energy engineering with the Mechanical and Materials Engineering Department, Queen's University, Kingston, Ontario, Canada. Email: pearce@me.queensu.ca

The author would like to thank the Appropedia Foundation and Lonny Grafman for helpful comments and assistance in making this work possible.

\begin{abstract}
Numerous studies have demonstrated that university students are capable of contributing to sustainable development while improving their academic skills. Unfortunately for many institutions, the expense of sending large cohorts of students on international service learning trips is prohibitive. Yet, students remain enthusiastic and well equipped to assist in sustainable development. This article reports on two pedagogical experiments in service learning that overcame this challenge by providing solutions to sustainable development problems using Appropedia.org, the site for collaborative solutions in sustainability, poverty reduction and international development. The course successfully used Appropedia (1) as a forum for students who were geographically dispersed, (2) for a whole-class writing collaboration, (3) to coordinate a sustainability-focussed outreach campaign to retrofit stop lights in communities throughout Pennsylvania and (4) to review class material with application to technologies for sustainable development.
\end{abstract}

\section{INTRODUCTION}

Although global conditions continue to reflect a marked underinvestment in sustainable development, a growing body of university student work (Domask 2007; Endreny 2004; Grusky 2000; Keen and Baldwin 2004; Mihelcic, Phillips and Watson 2006; Pearce, 2007a, 2007b; Sandekian, Amadei and Pinnell 2005; Weinberg 1999) has been shown to solve environmental and development problems on a small scale using service learning projects.

Service learning can be defined as a teaching method that combines community service with academic instruction as it focusses on critical reflective thinking and civic responsibility (Campus Compact 2000). Service learning benefits both the provider and the recipient of the service and requires that the service and the learning occur in tandem (Furco 1996). The evidence that service learning outcomes are positive for students, faculty, educational institutions and involved community partners has grown formidable (Bringle and Hatcher 1996; Cohen and Kinsey 1994; Driscoll, Holland, Gelmon and Kerrigan 1996; Giles and Eyler 1994; Kellogg Commission 1999; Panici and Lasky 2002; Pearce 2007a). A growing number of university service learning programs and courses address sustainable development. ${ }^{1}$ Programs such as the Kefalonia Program in Sustainable Community Development 
Published as: Joshua M. Pearce, "Appropedia as a Tool for Service Learning in Sustainable Development", Journal of Education for Sustainable Development, 3(1), pp.47-55, 2009. http://jsd.sagepub.com/cgi/content/abstract/3/1/45

(Zaferatos 2007) should be viewed as the ideal because not only do they offer students rich learning opportunities but they also directly partner with developing communities. However, although they are successful and useful, these programs lack the potential of universal replication because of their travel costs. This article reports on two pedagogical experiments that use virtual service learning to provide solutions to sustainable development problems without incurring travel expenses.

\section{SERVICE LEARNING FOR SUSTAINABLE DEVELOPMENT}

Educational institutions have the potential to provide an immense set of resources for sustainable development by assisting in the improvement and implementation of 'appropriate technologies' (ATs; Logan 1980). ATs are defined here as technologies that are easily and economically used from readily available resources by local communities in the developing world. ATs must meet the boundary conditions set by environmental, cultural, economic, and educational resource constraints of the local community (Pearce, 2007a, 2007b). Many top universities now feature courses ${ }^{2}$ dedicated to developing sustainable ATs in their engineering or science curricula. Sustainable development AT research, however, is far from ubiquitous. Although some limited research has been done on several ATs, the diffusion of these innovations has greatly lagged behind the demand by communities in the developing world.

One method of integrating AT research, development and diffusion into the university curriculum is to use 'virtual' service learning. When engaged in service learning, students are more motivated, work harder, learn more and are left with lasting benefits from their experience (Cohen and Kinsey 1994; Giles and Eyler 1994; Pearce 2001; Pearce and Russill 2003, 2005, 2006). Most important, when focussed on sustainable development, AT projects are highly engaging and motivational for students (Pearce, 2007a, 2007b). An AT wiki, Appropedia.org, provides an outlet for student research on ATs and thus offers a route for college students to directly contribute to sustainable development.

Appropedia acted as the community partner for the service learning projects described in this article, although the student work was meant to benefit anyone around the globe interested in the specific AT that the students studied. This virtual service learning approach represents a vast (and largely untapped) resource for accelerating sustainable development while enhancing course-based learning.

\section{MASSIVE MULTI-USER COLLABORATION IN SUSTAINABLE DEVELOPMENT: THE APPROPEDIA PLATFORM}

Appropedia is a wiki-based website like Wikipedia. It is the primary site for collaborative solutions in sustainability, poverty reduction and international development. The site has enormous potential to assist in sustainable development because it simplifies the administration of collaboratively organizing information, project examples, best practices and 'how to's'. It has already become the venue of choice for organizations like Engineers without Borders - Australia and Demotech and is set to expand rapidly as other organizations use its information transfer and collaboration capabilities (Pearce, Grafman, Colledge and Legg 2008). ${ }^{3}$ 
Published as: Joshua M. Pearce, "Appropedia as a Tool for Service Learning in Sustainable Development", Journal of Education for Sustainable Development, 3(1), pp.47-55, 2009. http://jsd.sagepub.com/cgi/content/abstract/3/1/45

Appropedia was used in the course 'PH261: Physics of Energy and the Environment', which studies the physical laws and processes that underlie environmental phenomena with a special focus on energy (mechanical, thermal and electrical). As the foundation of the Sustainability: Science and Policy program at Clarion University of Pennsylvania, the course imparts both a qualitative and quantitative understanding of the underlying physical processes so that technical, economic and social consequences of these laws and processes can be examined to better delineate the complex decisions related to human energy use and environmental issues. In fall 2007, PH261 was offered for the first time online using Appropedia as a tool to (1) share information with fellow students who may have never met, (2) collaborate on documents, (3) coordinate a sustainability-focussed service learning outreach campaign and (4) review physics with application to technologies for sustainable development. The participating class was made up of students from every academic year, although most were upper level. Most were majors in the sciences such as biology, environmental biology, geology or physics, but several came from non-scientific disciplines such as secondary education.

\section{Social Networking and Wiki Language}

Because PH261 never met in a classroom and even office hours were held with video Skype, the first assignment was designed for students to introduce themselves to one another. Students were asked to create a user account and to build a user page in Appropedia with pictures and information about themselves and their interests related to the class. ${ }^{4}$ This project enabled them to become familiar with using wikis. A wiki is a website in which a large number of participants are allowed to create and modify the content directly from their web browsers. Less than 10 per cent of the class had edited a wiki previously. Although the wiki language is relatively easy to learn, to do more than simple text formatting demands some study and experimentation. The content in Appropedia is under the GNU Free Document License, ${ }^{5}$ and having students become accustomed to following these intellectual property rules became valuable for the later assignments.

By first working on their own pages, students obtained the confidence to later help edit much more complex articles already in Appropedia. It should be noted that, although in a traditional classroom the need for networking is lessened considerably, a safe area to experiment with editing continues to be highly recommended for the use of any wiki in the classroom. Finally, the creation of user accounts allowed the instructor to track the work that the students did throughout the semester.

\section{Whole-Class Collaboration on Documents}

Next, to get the students accustomed to working together and to have a little fun with the wiki, students were asked to find and compile as many songs as they could with an environmental theme or message and then list them along with the reason why they were chosen. This assignment could include posting a review, lyrics, and links to audio or video with environmental content. In addition to generating an impressive list of environmentally themed songs for everyone to enjoy, the mini-project enabled the

class to discuss questions such as, 'Is the environment an important issue in contemporary culture?', on the password-protected webspace for the class. This project was the stepping-stone to much more 
Published as: Joshua M. Pearce, "Appropedia as a Tool for Service Learning in Sustainable

Development", Journal of Education for Sustainable Development, 3(1), pp.47-55, 2009.

http://jsd.sagepub.com/cgi/content/abstract/3/1/45

important whole-class collaborations, such as the creation of review lists for physics principles and devices covered in class and of frequently asked questions (FAQs) and referenced answers for their actual service learning project.

\section{Coordination of a Sustainability-Focussed Outreach Campaign}

The class partnered with the Sustainable Energy Fund of Central Eastern Pennsylvania, which was acting as an energy service company for local municipalities, to retrofit their incandescent traffic lights with LED lights. LEDs are much more efficient than traditional lighting, thus saving energy, reducing their environmental impact and moving the local municipalities closer to sustainability.

Appropedia was used to geographically coordinate the information campaign so students did not replicate their efforts by studying the same area. Each student chose a municipality and did a traffic light audit of all its intersections. Each then calculated the savings in economic and environmental terms achieved by upgrading to the more advanced LED light sources. The students collaborated on shared documents such as an LED FAQ to help make each one's individual campaign as successful as possible. Finally, each student wrote to a local decision maker and either shared the study in writing or set up an appointment to meet in person to walk through the calculations.

The savings from LED retrofits could be substantial. For example, the Borough of Clarion was operating only nine intersections containing 210 red, amber and green incandescent traffic signals and pedestrian crossings lights that were good candidates for conversion to LEDs. Each new LED module uses from 5 to $12 \mathrm{~W}$ (as compared to 69 to $116 \mathrm{~W}$ for incandescent bulbs) of electricity depending on its size and colour. The total annual reduction in energy consumption for Clarion after an LED retrofit was $66,000 \mathrm{~kW}-\mathrm{hrs}$ or $91 \%$ of the previous consumption (ECON 2007). This energy savings prevents about 70 tons of carbon dioxide emissions and provide the borough with an annual cost savings for electricity of $\$ 4,900$. Because LEDs have a long life and are maintenance free, the total annual savings is $\$ 7,000$. The simple payback period for this conservation opportunity was 4.3 years $(\$ 30,150$ of investment $\$$ 7,000 per year of savings) or, using a graphical method to convert to return on investment (ROI) equivalent, more than 20\% (Pearce and Uhl 2003).

Clarion Borough took advantage of a financing package that enabled them to obtain the LED lights immediately. Similarly the vast majority of the municipalities approached by the students have either retrofitted their lights with LEDs or are in the process of doing so as of this writing. Thus, this project moved municipalities in Pennsylvania towards sustainability by encouraging the use of an AT.

\section{Review of Physics with Technologies for Sustainable Development}

Another project, which proved to be the most pedagogically useful one, was an assignment to 'construct or fortify the information in Appropedia on an appropriate technology of your choice that has a positive environmental or energy related impact'. Students were asked to identify an AT that interested them through research, examples from former students or class content, the department's collection of 
Published as: Joshua M. Pearce, "Appropedia as a Tool for Service Learning in Sustainable Development", Journal of Education for Sustainable Development, 3(1), pp.47-55, 2009. http://jsd.sagepub.com/cgi/content/abstract/3/1/45

books/articles or the Internet. Students having trouble with a specific class topic (e.g., heat transfer) were asked to consider targeting a technology that uses that area of physics to help them review it (e.g., home insulation with straw bale construction). In addition, there are many incomplete topics already tagged in Appropedia as 'stubs', as well as a list of suggested projects from other Appropedians. ${ }^{6}$ Next, students coordinated their projects on the class category page that allowed for collaboration while eliminating duplication. Then, they researched the technical specifications of their chosen device, paying close attention to its underlying physics so they might understand how to improve its performance. Finally, students wrote an article (or several integrated articles) on their chosen AT for Appropedia. ${ }^{7}$ These articles generally contained a title, abstract, science principles (often with links to basic definitions in Wikipedia), cultural/regional context, required materials/tools/skills, technical specifications and sometimes drawings and schematics, costs, common mistakes and sources.

This assignment provided students with an opportunity to directly participate in global collaboration to support sustainable development. Appropedia pages are being ported to the One Laptop per Child (OLPC) project, which has enjoyed widespread publicity as the '\$100 laptop' program. If the student work was of high enough quality and fit the necessary guidelines, ${ }^{8}$ there was a real chance it might be translated and used by millions of children all over the world to improve their lives by building and using sustainable technology plans made available when they receive their donated laptops. The student authors with the best work were offered credit for furthering their projects in independent study courses. For example, PH261 projects in solid-state lighting and removal of arsenic from groundwater were expanded into full research projects the following semester.

Overall this project proved successful at both assisting students to learn course material and providing high-quality content in the open source AT movement. ${ }^{9}$ Students were motivated to do high-quality work. By tracking the history files in Appropedia, it was possible to see that students spent significantly more time working on their Appropedia projects than they did on their conventional homework projects assigned and tracked in Blackboard. The discussions in the Blackboard Discussion Board about the project were also all positive and encouraging. Students found the work in Appropedia exciting and interesting. Several noted that the wiki coding was challenging. At the end of the semester, the students made only positive comments about the project in their teacher evaluations, and several students expressed gratitude for being exposed to the assignment. The Appropedia Foundation was also pleased with the students' work because it had filled some of the holes in Appropedia's coverage of energy. Some PH261 projects were even chosen to be highlighted on Appropedia's welcome page.

\section{Challenges of the Approach}

Although the use of Appropedia in the classroom offers many advantages, it also has some challenges. It is necessary for the instructor to become adept at wiki markup to be able to help the students overcome problems and to fix major errors as students work through the more difficult editing features such as tables. In particular it is useful if the professor understands the use of templates, which allow short code to be inserted on a page to do complicated tasks. 
Published as: Joshua M. Pearce, "Appropedia as a Tool for Service Learning in Sustainable Development", Journal of Education for Sustainable Development, 3(1), pp.47-55, 2009. http://jsd.sagepub.com/cgi/content/abstract/3/1/45

A template should be used to place a notice box on the top of all student pages to warn other Appropedia users not to edit the student pages until the course is completed, ${ }^{10}$ thereby averting the major risk associated with this approach: other people can edit student pages during the course of the semester. In general, the Appropedia user community was helpful and offered advice in the discussion tabs. However, vandals attacked several student pages. Fortunately, information cannot be destroyed in the wiki, so any vandalism can be easily reverted. One feature of Appropedia that can be helpful in ensuring students that their work has not been vandalized is the 'watchlist' feature, which enables students to set up the wiki to notify them by email if anyone edits a page they have chosen to watch. This feature is useful for tracking any asynchronous comments or changes made by reviewers of their work after the editing moratorium is lifted at the end of grading.

Finally, all information posted in the wiki is open, which can inhibit frank classroom discussion on difficult or contentious topics. For conventional classes that include the wiki as a project, this is not a problem, but for online courses, some means of password-protected space is necessary to enable students to feel safe to express their viewpoints in a cultivating and open learning atmosphere. In this case, a password-protected Blackboard webspace for the class was used for the majority of course discussions. For universities without a commercial web-based platform like Blackboard there are now many free software e-learning platforms - also known as course management systems (CMS), learning management systems (LMS) or virtual learning environments (VLE) - such as Moodle, ATutor or OLAT, among many others.

\section{CONCLUSION}

Applying service learning to sustainable development offers an enormous opportunity for both science and engineering programs at educational institutions. Such service learning does not need to be geographically proximal. This article shows how students dispersed geographically and unable to perform a conventional on-site service learning project were able to contribute to sustainable development using Appropedia.org both in their local areas and for sustainable information content to be used all over the world. The service learning approach represents a vast (and largely untapped) resource for accelerating sustainable development while enhancing course-based learning, as content developed for Appropedia can assist those building local knowledge and networks into what comprises an emerging 'Global Learning Space for Sustainable Development' (Fadeeva and Mochizuki 2007).

\section{REFERENCES}

Bringle, R. G., and J. A. Hatcher. 1996. 'Implementing service learning in higher education', Journal of Higher Education, 67:221-39.

Campus Compact National Center for Community Colleges. 2000. Introduction to Service Learning Toolkit. Providence, RI: Brown University Press.

Cohen, J., and D. F. Kinsey. 1994. 'Doing Good and Scholarship: A service learning study', Journalism 
Published as: Joshua M. Pearce, "Appropedia as a Tool for Service Learning in Sustainable Development", Journal of Education for Sustainable Development, 3(1), pp.47-55, 2009. http://jsd.sagepub.com/cgi/content/abstract/3/1/45

Educator, 48 (4):4-14.

Domask, J. J. 2007. 'Achieving Goals in Higher Education: An experiential approach to sustainability studies', International Journal of Sustainability in Higher Education, 8 (1):53-68.

Driscoll, A., B. Holland, S, Gelmon and S. Kerrigan. 1996. 'An Assessment for Service Learning: Comprehensive case studies of impact on faculty, students, community and institution', Michigan Journal of Community Service Learning, 3:66-71.

ECON Opportunities, Inc. 2007. Traffic Light Technical Energy Analysis for the Borough of Clarion Pennsylvania. Reading, PA: ECON Opportunities, Inc.

Endreny, T. 2004. 'Storm Water Management for Society and Nature via Service Learning, Ecological Engineering and Ecohydrology', International Journal of Water Resources Development, 20 (3):44562.

Fadeeva, Z., and Y. Mochizuki. 2007. 'Regional Centres of Expertise: Innovative networking for education for sustainable development', Journal of Education for Sustainable Development, 1 (2):22937.

Furco, A. 1996. 'Service Learning: A balanced approach to experiential education', in Expanding Boundaries: Serving and learning. Washington DC: Corporation for National Service, 2-6.

Giles, D. E., and J. Eyler. 1994. 'The Theoretical Roots of Service Learning in John Dewey: Toward a theory of service learning', Michigan Journal of Community Service, 1 (1):77-85.

Grusky, S. 2000. 'International Service Learning: A critical guide from an impassioned advocate', Behavioral Scientist, 43 (5):858-67.

Keen, C., and E. Baldwin. 2004. 'Students Promoting Economic Development and Environmental Sustainability: An analysis of the impact of involvement in a community-based research and servicelearning program', International Journal of Sustainability in Higher Education, 5 (4):384-94.

Kellogg Commission on the Future of State and Land-Grant Universities. 1999. Returning to Our Roots: The engaged institution. Washington, DC: National Association for Higher Education.

Logan, P. F. 1980. 'Physics in Appropriate Technology', Physics in Technology, 11:187-92.

Mihelcic, J. R., L. D. Phillips and D. W. Watkins. 2006. 'Integrating a Global Perspective into Education and Research: Engineering international sustainable development', Environmental Engineering Science, 23 (3):426-38. 
Published as: Joshua M. Pearce, "Appropedia as a Tool for Service Learning in Sustainable Development", Journal of Education for Sustainable Development, 3(1), pp.47-55, 2009. http://jsd.sagepub.com/cgi/content/abstract/3/1/45

Panici, D., and K. Lasky. 2002. 'Service Learning's Foothold in Communication Scholarship', Journalism \& Mass Communication Educator, 57 (2):113-25.

Pearce, J. 2001. 'The Use of Self-Directed Learning to Promote Active Citizenship in Science, Technology, and Society Classes', Bulletin of Science, Technology, and Society, 21 (4):312-21.

Pearce, J. M. 2007a. 'Teaching Physics Using Appropriate Technology Projects', The Physics Teacher, 45:164-67.

Pearce, J. M. 2007b. 'Teaching Science by Encouraging Innovation in Appropriate Technologies for Sustainable Development', Proceedings of the $11^{\text {th }}$ Annual National Collegiate Inventors and Innovators Alliance Conference, 159-67.

Pearce, J. M., L. Grafman, T. Colledge and R. Legg. 2008. 'Leveraging Information Technology, Social Entrepreneurship and Global Collaboration for Just Sustainable Development' Proceedings of the $12^{\text {th }}$ Annual National Collegiate Inventors and Innovators Alliance Conference, 201-10. Available at http://www.nciia.org/conf08/assets/pub/pearce.pdf (accessed 8 September, 2008).

Pearce, J. M., and C. Russill. 2003. 'Student Inquiries into Neglected Research for a Sustainable Society: Communication and application', Bulletin of Science, Technology and Society, 23 (4):311-20.

Pearce, J. M., and C. Russill. 2005. 'Interdisciplinary Environmental Education: Communicating and applying energy efficiency for sustainability', Applied Environmental Education and Communication, 4 (1): 65-72.

Pearce, J. M., and C. Russill. 2006. 'Commissioned Assignments in Environmental Policy', Academic Exchange Quarterly, 10 (1):80-84.

Pearce, J. M., and C. Uhl. 2003. 'Getting It Done: Effective sustainable policy implementation at the university level', Planning for Higher Education, 31 (3):53-61.

Sandekian, R., B. Amadei and M. Pinnell. 2005. 'A Summary of the Workshop on Integrating Appropriate-Sustainable Technology and Service-Learning in Engineering Education', Proceedings of the 2005 American Society for Engineering Education Annual Conference \& Exposition, American Society for Engineering Education.

Weinberg, A. S. 1999. 'The University and the Hamlets: Revitalizing low-income communities through university outreach and community visioning exercises', American Behavioral Scientist, 42 (5):800-13.

Zaferatos, N.C. 2007. 'Sustainable Planning Education as Intercultural Service Learning: Kefalonia Program in sustainable community development', Journal of Education for Sustainable Development, 1 (2):199-208. 
1 For example, several dozen campuses host robust programs run under the Engineers for a Sustainable World, which routinely takes students to developing countries to work collaboratively with local communities on engineering problems. Another excellent example is the Engineering World Health organization, which runs out of Duke University; see http://www.ewh.org (accessed 9 September, 2008). This program trains students in electric medical systems and provides them with the opportunity to travel to developing countries and actually put their skills to use.

2 See for example: Caltech - E105: Product Design for the Developing World, http://www.its.caltech.edu/ e105/index.htm (accessed 9 September, 2008); Colorado University CVEN 4838/5838: Engineering for the Developing World, http://www.edc-cu.org/pdf/EDW07.pdf (accessed 9 September, 2008); MIT - D-Lab, http://web.mit.edu/d-lab/ (accessed 9 September, 2008), The University of Michigan even has developed an AT degree concentration, http://www.engin.umich.edu/students/bulletin/interdisc/concentrations.html (accessed 9 September, 2008)

3 Since 1 October, 2006, the number of Appropedia registered users has increased by a factor of 15 , and as of 9 September, 2008, there are more than 1,200. The number of edits has also increased by more than a factor of 10 to 50,000. Many of these edits were new articles. The article count increased by almost a factor of 100, from 128 to the current 12,483. With these new articles came many new page views, which is a quantitative method of determining reader growth. The page views have increased from 74,000 to approximately 5 million. Current statistics can be found at http://www.appropedia.org/Special:Statistics

4 For tips on making a good user page see http://www.appropedia.org/Help:Contents (step-by-step instructions; accessed 9 September, 2008) and the more detailed guidelines at http://en.wikipedia.org/wiki/Wikipedia:How to edit a page (accessed 9 September, 2008).

5 The GNU FDL means that anything students post can be copied, modified and redistributed so long as the new version grants the same freedoms to others and acknowledges the author (student) of the Appropedia article used. In addition, copyrighted work is not allowed to be posted. For complete details, see http://www.appropedia.org/Appropedia:Copyright (accessed 9 September, 2008).

6 Stubs are articles that have been started but need a lot of work: see

http://www.appropedia.org/Category:Stubs (accessed 9 September, 2008). Suggested projects are concepts created by other users that need additional development http://www.appropedia.org/Category:Suggested projects (accessed 9 September, 2008).

7 Based on the developmental needs addressed the devices were categorized to make them easy to find in Appropedia. (e.g., [[Category:Food and Agriculture]]). Each time a category is added to the page, a link to the student's page is also added in the category list. Finally students were asked to link their article (by placing double brackets around words in other Appropedia articles) that mention their articles' name and to place their article in the highlighted portal content (e.g., Portal:Energy).

8 For more information about the one laptop per child initiative see (accessed 9 September, 2008) http://www.appropedia.org/OLPC bundle frontpage; http://wiki.laptop.org/go/Home

9 A small improvement was observed in the student average grades compared to those for the course given two years earlier by the same instructor; the evaluations of the instructor also improved. These observations represent preliminary findings as several variables changed from the earlier course (e.g., moving it online, using Appropedia, using a different final exam format, etc.). The grades improved by less than half a letter grade and the instructor evaluations improved by 5 per cent. Further work is necessary to quantify the observations made in this work with a larger number of classes.

10 The notice reads. 'This page is part of a project for MECH370, a Queen's University class on materials processing. Please do not edit this page before Dec. 1, 2008 unless you are in that class, but 
feel free to make comments using the discussion tab. For this text to appear on a student's page in a notice box they insert the code $\{\{\mathrm{MECH} 370\}\}$ http://www.appropedia.org/Template:MECH370 (accessed 9 September,, 2008). 